\title{
Ultrathin collagen type I films formed at the air-water interface
}

\author{
Shanshan Zhang ${ }^{1} \cdot$ Yue Liu $^{1,2} \cdot$ Rainhard Machatschek ${ }^{1,2} \cdot$ Andreas Lendlein $^{1,2} \oplus$
}

Received: 18 September 2021 / Accepted: 28 October 2021 / Published online: 14 February 2022

(c) Helmholtz-Zentrum Hereon 2022

\begin{abstract}
Collagen-based biomaterials with oriented fibrils have shown great application potential in medicine. However, it is still challenging to control the type I collagen fibrillogenesis in ultrathin films. Here, we report an approach to produce cohesive and well-organized type I collagen ultrathin films of about $10 \mathrm{~nm}$ thickness using the Langmuir-Blodgett technique. Ellipsometry, rheology, and Brewster angle microscopy are applied to investigate in situ how the molecules behave at the air-water interface, both at room temperature and $37^{\circ} \mathrm{C}$. The interfacial storage modulus observed at room temperature vanishes upon heating, indicating the existence and disappearance of the network structure in the protein nanosheet. The films were spanning over holes as large as $1 \mathrm{~mm}$ diameter when transferred at room temperature, proving the strong cohesive interactions. A highly aligned and fibrillar structure was observed by atomic force microscopy (AFM) and optical microscopy.
\end{abstract}

\section{Introduction}

Among the 28 known collagen types in the human body [1], type I collagen (Co-I) is the most abundant, e.g., as the basic building block of most connective tissues [2]. The organization of this fibrillar protein varies from a hierarchical structure on 7 hierarchical levels in bone [3] to an orthogonal grid of highly oriented and aligned fibrils in corneal stroma [4]. On the molecular level, Co-I is a heterotrimer molecule composed of three polypeptide chains arranged into a triplehelical conformation with approximately $300 \mathrm{~nm}$ in length and $1.5 \mathrm{~nm}$ in width [5]. The triple-helical domain is characterized by the Glycine-X-Y amino acid repeats, where often $\mathrm{X}$ is a proline, and $\mathrm{Y}$ is a hydroxyproline [6]. Moreover, the hydroxylysine residues in the collagen chains can participate in intramolecular and intermolecular cross-linking [7].

Owing to its abundance and availability, Co-I is an interesting biomaterial for a broad field of applications such as tissue regeneration [8], coatings of cell culture substrates [9], or implant coatings [10]. All of these applications necessitate the reconstitution of collagen after extraction

Andreas Lendlein

Lendlein@uni-potsdam.de

1 Institute of Active Polymers and Berlin-Brandenburg Center for Regenerative Therapies, Helmholtz-Zentrum Hereon, 14513 Teltow, Germany

2 Institute of Chemistry, University of Potsdam, 14476 Potsdam, Germany and purification into the fibrillated state found in nature. In acidic solution, it has been observed that collagen molecules spontaneously assemble into larger fibrils upon heating [11]. The process, which requires a desolation of molecules, is driven by the entropy-gain of the water molecules at a higher temperature. This suggests that collagen dehydration can be used to control fibrillation and assembly.

In consequence, the Langmuir-Blodgett (LB) technique has been used to control fibrillation and orientation of Co-I in thin films $[12,13]$. When assembled at the air-water interface, Co-I already is in a partly dehydrated state, and further dehydration can be achieved by lateral compression. Here, we investigate how the different hydration states at the airwater interface affect the organization of Co-I, both at room temperature and $37^{\circ} \mathrm{C}$ (see Fig. 1). To this end, the Co-I acid solution was spread on phosphate buffered (PBS) subphases at $\mathrm{pH}$ 7.4. The adsorption behavior and a real molecular concentration of the interfacial collagen layer were calculated via ellipsometry. Structure formation upon compression was followed by means of Brewster angle microscopy (BAM) in situ on the micrometer scale and on transferred films in the nanometer range. The thermal behavior was further studied using interfacial rheology and by transferring films on porous substrates to probe their cohesiveness. A detailed description of the experimental part can be found in the Supplementary Information (SI). 


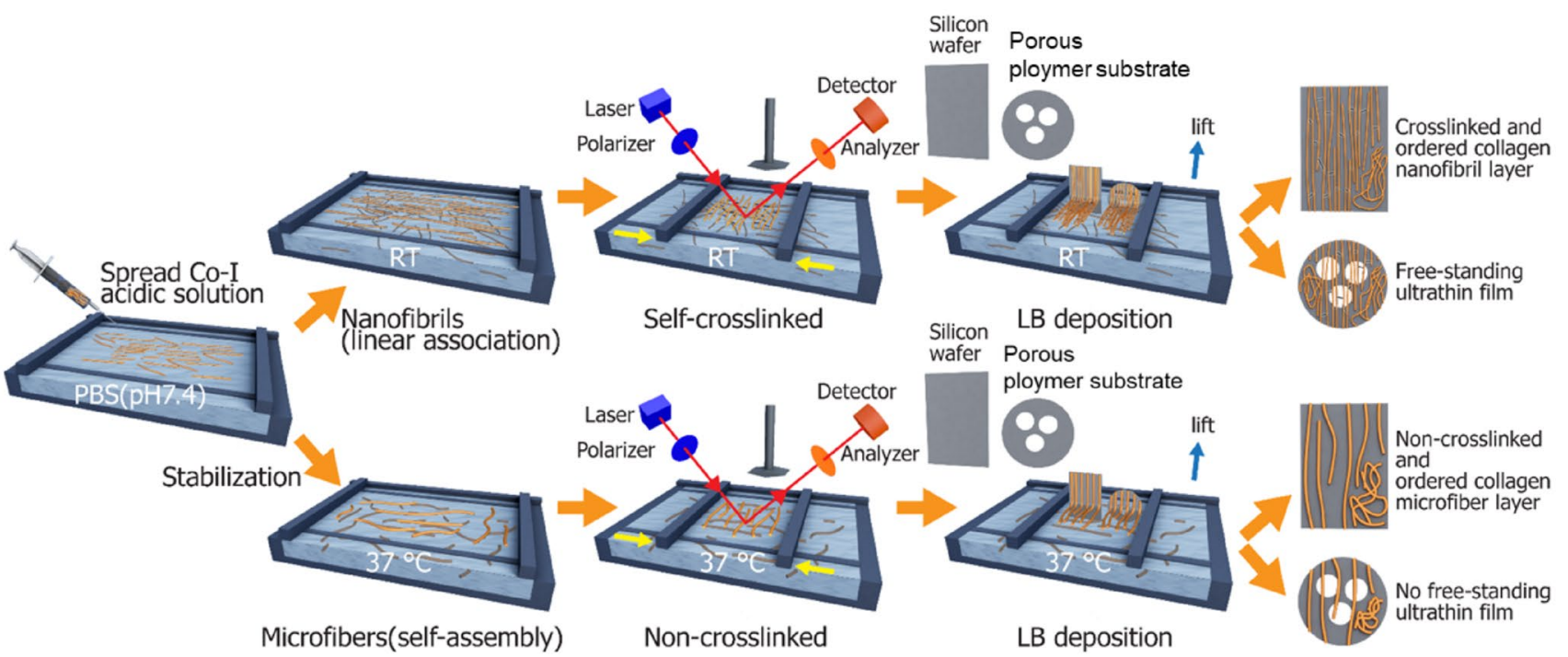

Fig. 1 Schematic of the formation of collagen-based ultrathin films via $\mathrm{LB}$ method at $24{ }^{\circ} \mathrm{C}$ and $37{ }^{\circ} \mathrm{C}$. The Co-I acidic solution was spread on the PBS subphase with $\mathrm{pH} 7.4$ at different temperatures. At RT, Co-I molecules tended to form nanofibrils in a linear association way during the stabilization. After compression, the nanofibrils formed a cohesive film and were transferred to silicon wafers

\section{Results and discussion}

The determination of the areal concentration of soluble surfactants such as proteins in monolayers is challenging. Here, we used the dependence of the ellipsometric angle delta $(\Delta)$ on the areal concentration of collagen for its quantification. $\Delta$ was plotted against the reciprocal trough area $A$ for different compression rates of 30,50 and $70 \mathrm{~mm} / \mathrm{min}$ (see SI Fig. S1) and the mass of adsorbed and porous polymer substrates. When the subphase was heated to $37^{\circ} \mathrm{C}$, Co-I molecules were more likely self-assembled into microfibers during stabilization. The film had a less cohesive structure after compression. At last, no free-standing ultrathin film was found on the porous substrate

$m_{\text {protein }}=\frac{s}{k}$

Following this procedure we could determine a remaining mass at the surface of $85 \pm 9 \mu \mathrm{g}$. Considering the total amount of Co-I, which was spread on the surface, being $0.2 \mathrm{ml} * 800 \mu \mathrm{g} / \mathrm{ml}=160 \mu \mathrm{g}$, roughly $53 \mathrm{wt} \%$ of the protein remained at the interface, the other molecules went into the subphase.

Taking $300 \mathrm{kD}$ as the molar mass of Co-I molecules [15], the number of Co-I molecules was $1.71 * 10^{14}$.

$N=\frac{m}{M} *$ Avogadro constant $=\frac{85 \mu \mathrm{g}}{300,000 \mathrm{~g}} * 6.02 * 10^{23}=1.71 * 10^{14}$

protein was determined according to a relationship established in our previous work [14]:

$\Delta=180.4+k * \frac{m_{\text {protein }}}{A}$

where $k=13 \mathrm{~cm}^{2} / \mu \mathrm{g}$ for collagen and $m_{\text {protein }}$ is the total protein mass. From the slope $(s)$ of the plots, we calculate $m$ according to:
Assuming a dense packing of the molecules in a single layer, the total area covered by the cylindrical collagen molecules is given by

$A^{\prime}=N * L * D=1.71 * 10^{14} * 1.5 \mathrm{~nm} * 300 \mathrm{~nm}=770 \mathrm{~cm}^{2}$

With the area of the trough used for the ellipsometry experiments being $648 \mathrm{~cm}^{2}$, which approaches the previously 
calculated value of $770 \mathrm{~cm}^{2}$, we conclude that upon spreading, Co-I molecules organize into an ultrathin film with the areal concentration close to a densely packed monolayer. However, AFM images (see below) indicate that the packing of molecules is rather loose in that stage, so the initial film thickness corresponds to few layers of Co-I. Ellipsometry clearly showed that no molecules were lost upon compression, so the layer thickness and/or packing density increased according to the area reduction.

BAM images showed that Co-I was not forming any micrometer-sized structures after spreading (Fig. 2A) except for some undissolved particles. Upon compression, larger and aligned dark structures were observed. However, the layers formed at higher temperature have more but shorter aggregates (dark ellipses and dots). This observation can be explained by the fiber formation of tropocollagen, leading to the increase of diameter. The reason that the aggregates became smaller might be a denser packing in collagen fibrils. Figure $2 \mathrm{~B}$ demonstrates the surface pressure-surface area per mass isotherms at $\mathrm{RT}$ and $37^{\circ} \mathrm{C}$. At both temperatures, the surface pressure increases continuously upon compression. Nevertheless, the slightly less pronounced increase of surface pressure of the film at $37{ }^{\circ} \mathrm{C}$ indicates that the surface pressure arises from short-range repulsive interactions in a condensed state, which are not very temperature sensitive.

The dynamic shear response of the Langmuir films during compression at RT and $37{ }^{\circ} \mathrm{C}$ was measured by interfacial rheology. The variation of the surface pressure and viscoelastic modulus vs area per mass is plotted in Fig. 2C. At RT, the storage modulus of the film started to become detectable in our setup when the area per mass of the Co-I molecules reached $0.17 \mathrm{~mm}^{2} / \mathrm{ng}$. After a sudden fluctuation, which is a consequence of the system working close to the detection threshold, the film experienced an exponential increase (linear in logarithmic scale) of the storage modulus with the reduction of the film surface area. This observation suggests that a cohesive interaction between the Co-I nanofibrils was introduced when they were laterally close to each other. A reasonable explanation is that the exposed hydrophilic residues along the collagen nanofibrils tended to form hydrogen bonds when they were compressed to a certain minimum distance. Different from the situation at low temperature, the film formed at $37{ }^{\circ} \mathrm{C}$ did not have a detectable storage modulus during the whole experiment. A possible explanation is that the heat or additional desolvation caused a conformation change of the protein, leaving the hydrophobic parts directed toward the outside of the self-assembled microfibers. Therefore, the weaker interaction between the hydrophobic segments lead to the feeble interlinking in the film at $37^{\circ} \mathrm{C}$.

The morphology of films deposited via Langmuir Blodgett transfers on silicon wafers is shown in Fig. 3A. At RT, the collagen film forms a compact layer consisting of nanofibrils with highly ordered alignment. It is known that in an acidic solution with a 95\% concentration, collagen forms gels [15]. At the interface, we prepare a similar highly dense collagen solution. The non-zero shear storage modulus suggests that in that state, the external macroscopic forces can be transferred into the densely packed molecular assembly, causing molecular rearrangements and in consequence, a parallel alignment upon compression. This linear pattern is also found in the image of the film formed at $37^{\circ} \mathrm{C}$. However, the film appears less organized. Another sound proof of the existence of a cohesive network in the collagen film formed at RT is that this film can nearly cover an area of $1 \mathrm{~mm}$ in diameter while this is not possible for films transferred at $37{ }^{\circ} \mathrm{C}$ (Fig. 3B). Interestingly, the free-standing film was able to support the growth of PBS crystals upon drying, which confirms supporting the adhesion of the crystals. A magnified view (Fig. 3B(e)) revealed that the free-standing film consists of groups of parallel overlapping nanofibrils.

The morphology and thickness of collagen layers on silicon wafers formed at RT and $37{ }^{\circ} \mathrm{C}$ were further analyzed by AFM. On the one hand, the compression force generated by the lateral movement of the barriers are not evenly distributed in all collagen molecules. On the other hand, some part of the film is stretched by the convergent flow during LB deposition [16]. Thus, both of the films contain an ordered phase and a disordered phase. Figure 4A displays the stretched area of the film formed at RT, which consists of straight and highly ordered nanofibrils (see Fig. 4B for magnified image), while the dark part in Fig. 4C consists of nanofibrils forming a random network structure (see Fig. 4D for magnified image). In comparison, the fibers from the stretched part of the film formed at $37{ }^{\circ} \mathrm{C}$ become thicker 

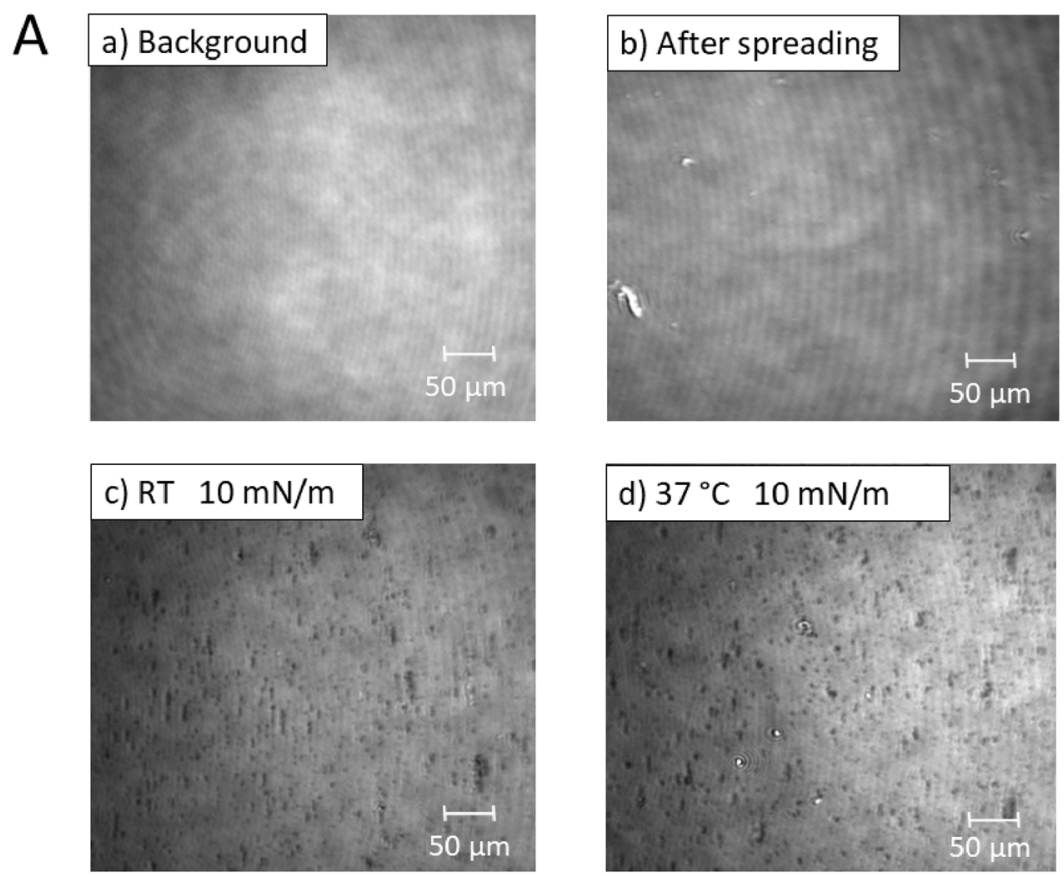

B
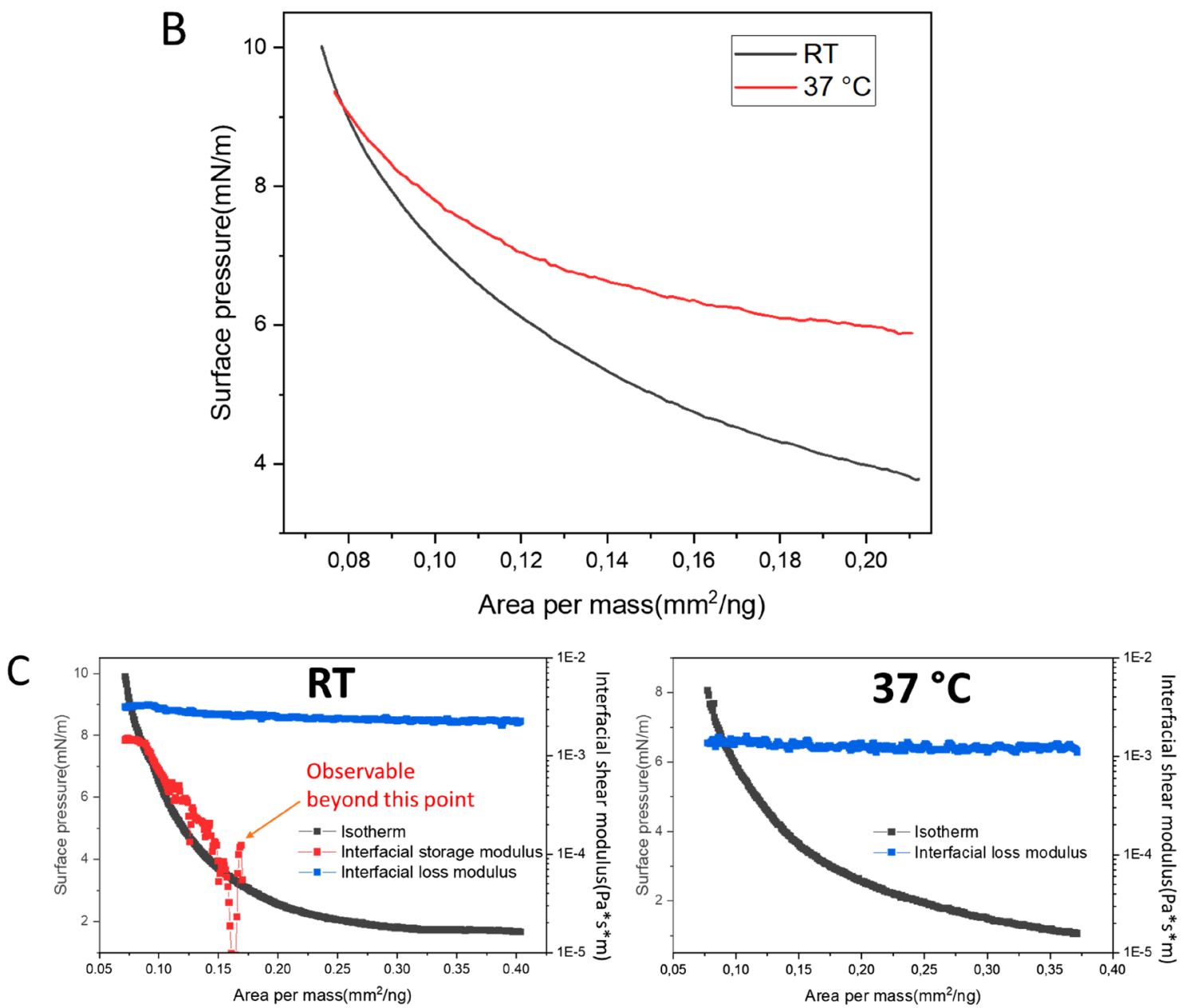
4Fig. 2 (A) Images taken by Brewster angle microscopy. (a) Surface of clean PBS subphase; (b) Surface after spreading $0.2 \mathrm{ml} \mathrm{Co-I} \mathrm{solution;}$ (c, d) Co-I monolayer formed at air-water interface at RT and $37{ }^{\circ} \mathrm{C}$ with a surface pressure $10 \mathrm{mN} / \mathrm{m}$. (B) Compression isotherm of Co-I with compression rate $10 \mathrm{~mm} / \mathrm{min}$ at RT and $37^{\circ} \mathrm{C}$. (C) Compression isotherm including interfacial shear moduli of Co-I formed at RT and $37{ }^{\circ} \mathrm{C}$. At $37{ }^{\circ} \mathrm{C}$, the interfacial storage modulus was not detectable. Black cubes stand for surface pressure, red cubes stand for interfacial storage modulus, and blue cubes stand for interfacial loss modulus and are arranged in an isolated and loosely way as Fig. 4E and $\mathrm{F}$ present. And its random phase (see Fig. 4G and $\mathrm{H}$ ) shows a slightly compaction and alignment. Based on the height profiles (see Fig. 4J and L) analyzed via scratching test, the average thicknesses of the film formed at RT and $37{ }^{\circ} \mathrm{C}$ are $9.7 \pm 0.6 \mathrm{~nm}$ and $8.2 \pm 0.6 \mathrm{~nm}$, respectively. The main reason that causes the reduction of the thickness of the collagen nanosheet after heating is probably the collagen molecules self-assembled into more tight and dense fibers
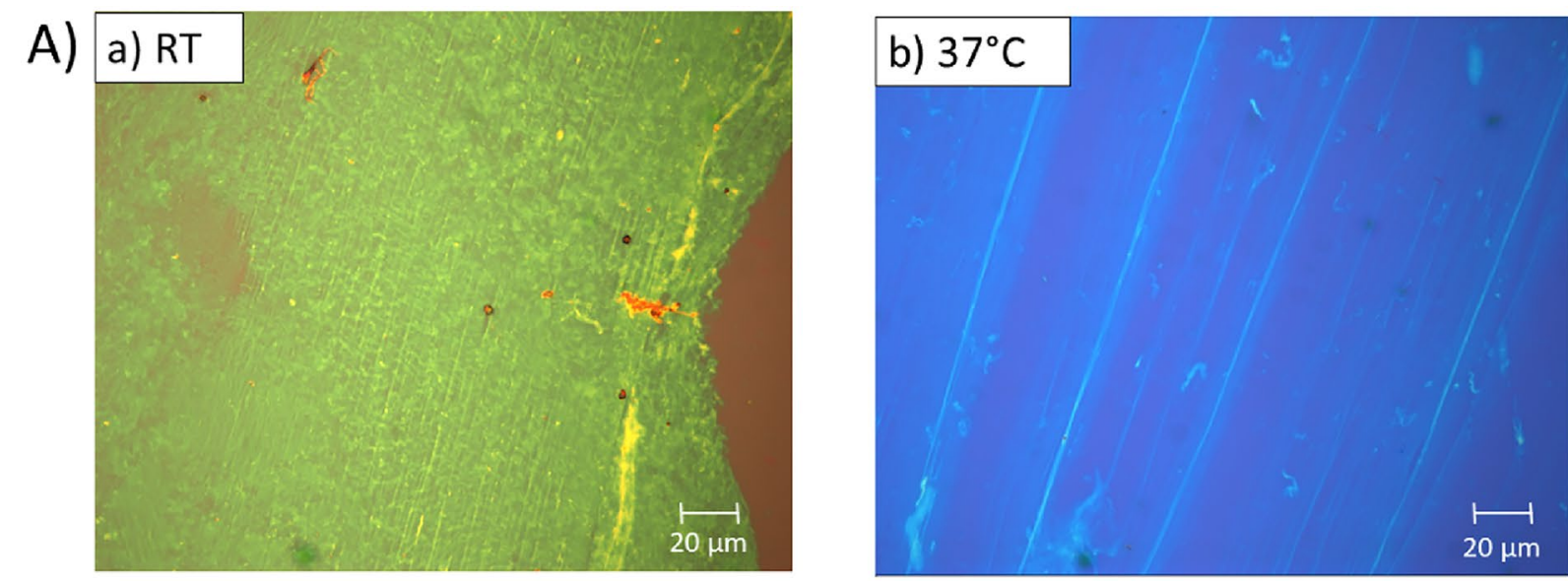

B)
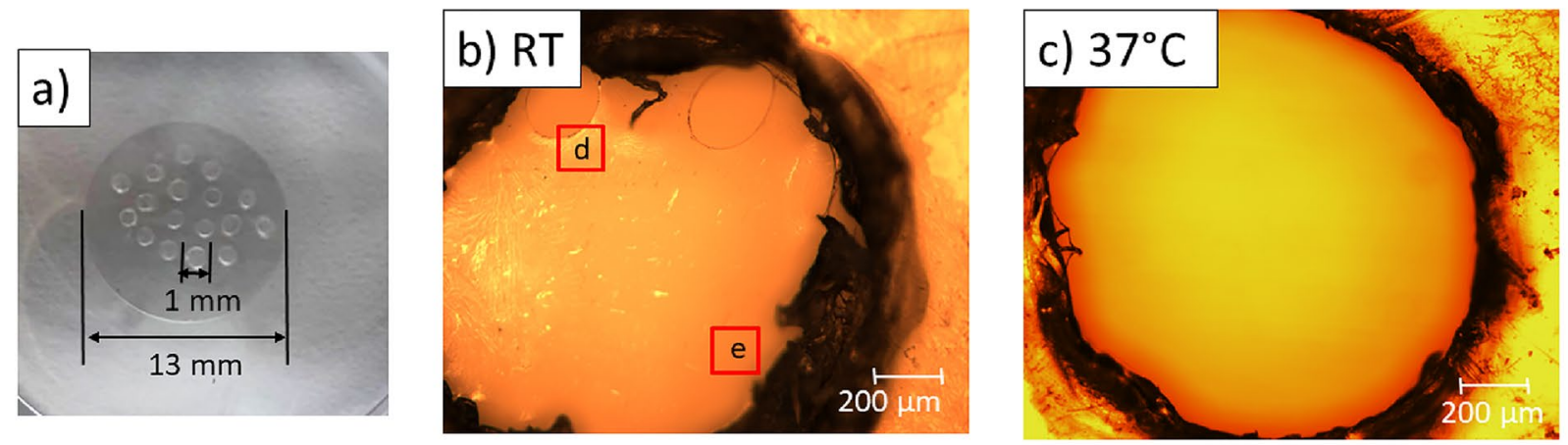

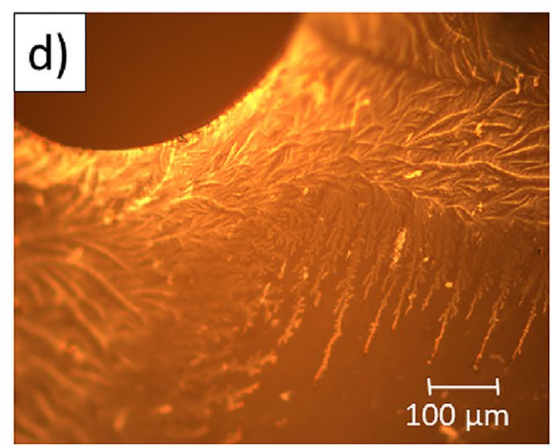

Fig. 3 Optical microscopy images of Co-I film on Si wafer and freestanding film covered on porous polycarbonate disk, which is all transferred via Langmuir-Blodgett method. (A-a) Co-I film formed at RT with alignments; (A-b) Co-I film formed at $37{ }^{\circ} \mathrm{C}$ with selfassembled fibrils; (B-a) Porous polymer substrate with hole size of

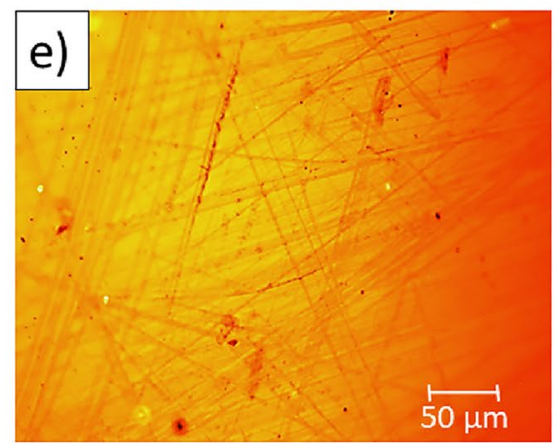

$1 \mathrm{~mm}$ diameter; (B-b, d, e) Free-standing film was found covering the hole after deposition at RT. The snowflake-like crystals came from the residual phosphate buffered saline and stretched Co-I fibrils can be observed in the film. (B-c) No free-standing film was found covering the hole after deposition at $37^{\circ} \mathrm{C}$ 

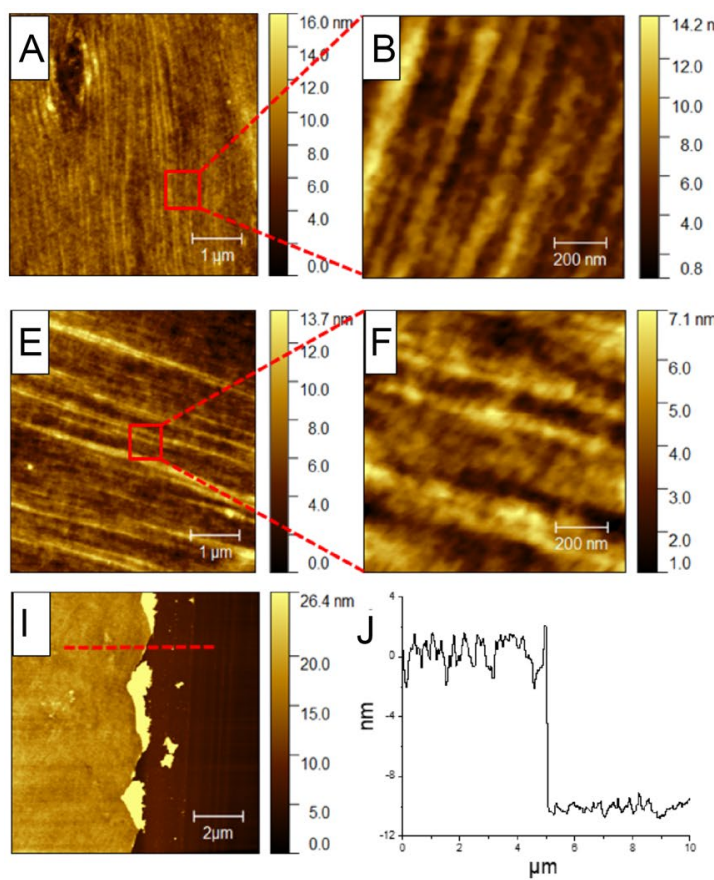

Fig. 4 AFM images of the Langmuir-Blodgett deposited ultrathin film formed at RT and $37{ }^{\circ} \mathrm{C}$ on Si wafer and scratch analysis. (A) stretched area of ultrathin film at RT with a compact alignment of collagen fibrils; (B) fine morphology of selected area in (A); $(\mathbf{C})$ unstretched area of ultrathin film at RT with a random structure; (D) fine morphology of selected area in (C); (E) stretched area of ultrathin film at $37{ }^{\circ} \mathrm{C}$ with a loose alignment of collagen fibrils;

\section{Conclusion}

In this study, the organization of Co-I molecules in acetic acid solution at the air-water interface was investigated at $\mathrm{RT}$ and $37^{\circ} \mathrm{C}$. It was shown by means of ellipsometry that the molecules organize in a film with close to monolayer coverage, which is condensed upon compression. Due to the partial dehydration at the air-water interface, a cohesive nanofibrillar network occurs already at RT, and further compression induces both fibrillation and fiber alignment. This cohesive structure vanishes during heating and fibrillation is mostly suppressed. Our results demonstrate how temperature can be used to control the morphology and strength of collagen coatings, allowing to generate both free-standing fibrillar sheets and soft, amorphous thin films of Co-I.

Supplementary Information The online version contains supplementary material available at https://doi.org/10.1557/s43580-021-00160-8.

Acknowledgments The authors acknowledge Manuela Keller for her assistance in AFM measurements and Ibrahim Ogunc for assistance with the graphics. This work was supported by the Helmholtz Association of German Research Centers through program-oriented
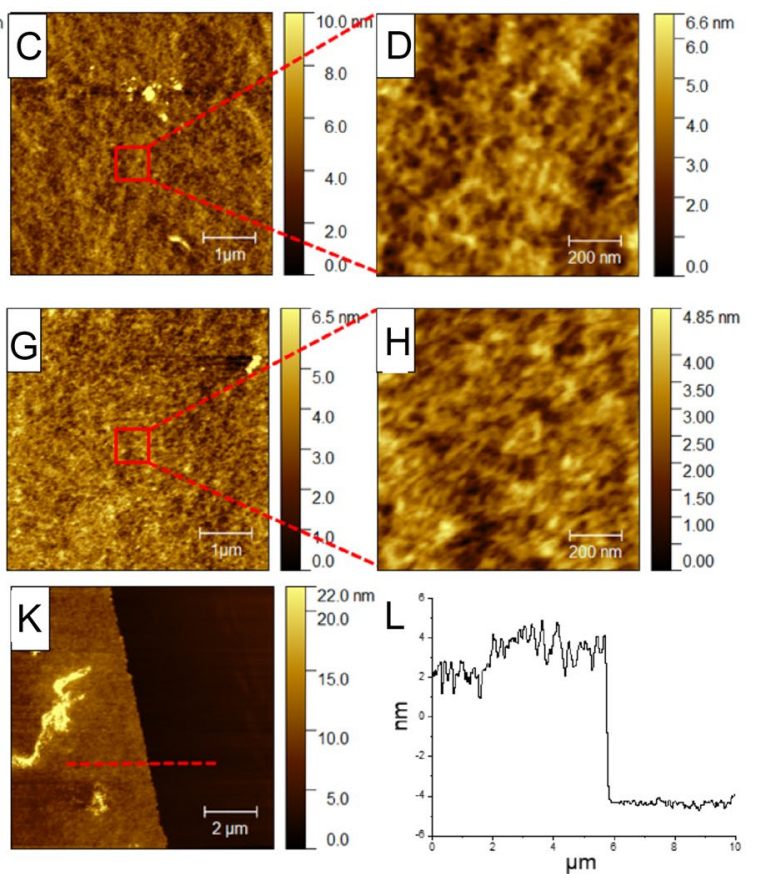

(F) fine morphology of selected area in $(\mathbf{E}) ;(\mathbf{G})$ unstretched area of ultrathin film at $37^{\circ} \mathrm{C}$ with a random structure; (H) fine morphology of selected area in $(\mathbf{G})$; (I) the scratch of film formed at RT; (J) the height topographic profile corresponding to the dashed lines marked in (I); (K) the scratch of film formed at $37{ }^{\circ} \mathrm{C}$; (L) the height topographic profile corresponding to the dashed lines marked in $(\mathbf{K})$

funding and through Helmholtz Graduate School for Macromolecular Bioscience (MacroBio, VH-GS-503).

Funding Open Access funding enabled and organized by Projekt DEAL.

Data availability The datasets generated and analyzed during the reported study are available from the corresponding author on a reasonable request.

\section{Declarations}

Conflict of interest The authors have no relevant financial or non-financial interests to disclose.

Open Access This article is licensed under a Creative Commons Attribution 4.0 International License, which permits use, sharing, adaptation, distribution and reproduction in any medium or format, as long as you give appropriate credit to the original author(s) and the source, provide a link to the Creative Commons licence, and indicate if changes were made. The images or other third party material in this article are included in the article's Creative Commons licence, unless indicated otherwise in a credit line to the material. If material is not included in the article's Creative Commons licence and your intended use is not permitted by statutory regulation or exceeds the permitted use, you will need to obtain permission directly from the copyright holder. To view a copy of this licence, visit http://creativecommons.org/licenses/by/4.0/. 


\section{References}

1. M.A. Karsdal, Biochemistry of collagens, laminins and elastin, in Structure Function and Biomarkers. ed. by M.A. Karsdal (Elsevier, London, 2016), p. 22

2. R. Tonndorf, D. Aibibu, C. Cherif, Mater. Sci. Eng. C 106, 110105 (2020)

3. S. Weiner, W. Traub, FASEB J. 6, 879 (1992)

4. K.M. Meek, C. Boote, Exp. Eye Res. 78, 503 (2004)

5. A. Leon-Lopez, A. Morales-Penaloza, V.M. Martinez-Juarez, A. Vargas-Torres, D.I. Zeugolis, G. Aguirre-Alvarez, Molecules 24, 4031 (2019)

6. M. Yamauchi, M. Sricholpech, Essays Biochem. 52, 113 (2012)

7. D.R. Eyre, M.A. Weis, J.J. Wu, Methods 45, 65 (2008)

8. C. Ma, H. Wang, Y. Chi, Y. Wang, L. Jiang, N. Xu, Q. Wu, Q. Feng, X. Sun, Appl. Mater. 22, 100902 (2021)
9. Y. Yang, K. Wang, X. Gu, K.W. Leong, Engineering 3, 36 (2017)

10. L. Pastorino, E. Dellacasa, S. Scaglione, M. Giulianelli, F. Sbrana, M. Vassalli, C. Ruggiero, Colloids Surf. B 114, 372 (2014)

11. K.E. Kadler, Y. Hojima, D.J. Prockop, J. Biol. Chem. 262, 15696 (1987)

12. A.J. Goffin, J. Rajadas, G.G. Fuller, Langmuir 26, 3514 (2010)

13. A.E. Sorkio, E.P. Vuorimaa-Laukkanen, H.M. Hakola, H. Liang, T.A. Ujula, J.J. Valle-Delgado, M. Osterberg, M.L. Yliperttula, H. Skottman, Biomaterials 51, 257 (2015)

14. T. Bhuvanesh, R. Machatschek, L. Lysyakova, K. Kratz, B. Schulz, N. Ma, A. Lendlein, Biomed. Mater. 14, 024101 (2019)

15. J. Gross, J.H. Highberger, F.O. Schmitt, PNAS 40, 679 (1954)

16. B.S. Liaw, F. Xing, D. Wang, F. Gao, J. Lu, J. Yu, X. Sun, X. Wang, Q. Feng, G. Zhang, L. Zhao, Colloids Surf. B 179, 48 (2019)

17. C. Ding, M. Zhang, K. Wu, G. Li, Polymer 55, 5751 (2014) 